\title{
Clinical efficiency of operating room-based sliding gantry CT as compared to mobile cone-beam CT-based navigated pedicle screw placement in 853 patients and 6733 screws
}

\author{
Sebastian IIle ${ }^{1,2} \cdot$ Lea Baumgart $^{1} \cdot$ Thomas Obermueller $^{1} \cdot$ Bernhard Meyer $^{1} \cdot$ Sandro M. Krieg $^{1,2}$ (D)
}

Received: 12 April 2021 / Revised: 30 July 2021 / Accepted: 24 August 2021 / Published online: 14 September 2021

(c) The Author(s) 2021

\begin{abstract}
Purpose Multiple solutions for navigation-guided pedicle screw placement are available. However, the efficiency with regard to clinical and resource implications has not yet been analyzed.

The present study's aim was to analyze whether an operating room sliding gantry CT (ORCT)-based approach for spinal instrumentation is more efficient than a mobile cone-beam CT (CBCT)-based approach.

Methods This cohort study included a random sample of 853 patients who underwent spinal instrumentation using ORCTbased or CBCT-based pedicle screw placement due to tumor, degenerative, trauma, infection, or deformity disorders between November 2015 and January 2020.

Results More screws had to be revised intraoperatively in the CBCT group due to insufficient placement (ORCT: 98, 2.8\% vs. CBCT: $128,4.0 \% ; p=0.0081$ ). The mean time of patients inside the OR (Interval 5 Entry-Exit) was significantly shorter for the ORCT group (ORCT: mean, [95\% CI] 256.0, [247.8, 264.3] min, CBCT: 283.0, [274.4, 291.5] min; $p<0.0001$ ) based on shorter times for Interval 2 Positioning_Incision (ORCT: 18.8, [18.1, 19.9] min, CBCT: 33.6, [32.2, 35.5] min; $p<0.0001$ ) and Interval 4 Suture-Exit (ORCT: 24.3, [23.6, 26.1] min, CBCT: 29.3, [27.5, 30.7] $\mathrm{min} ; p<0.0001$ ).

Conclusions The choice of imaging technology for navigated pedicle screw placement has significant impact on standard spine procedures even in a high-volume spine center with daily routine in such devices. Particularly with regard to the duration of surgeries, the shorter time needed for preparation and de-positioning in the ORCT group made the main difference, while the accuracy was even higher for the ORCT.
\end{abstract}

Keywords Cone-beam CT $\cdot$ Intraoperative imaging $\cdot$ Navigation $\cdot$ Pedicle screws $\cdot$ Sliding gantry CT

Portions of this paper have been previously presented at the virtual annual meeting of the German Spine Society (DWG), $12 / 9-11 / 2020$.

Sandro M. Krieg

Sandro.Krieg@tum.de

Sebastian Ille

Sebastian.Ille@tum.de

Lea Baumgart

Lea.Baumgart@mri.tum.de

Thomas Obermueller

Thomas.Obermueller@tum.de

\section{Introduction}

Several imaging modalities are available for the navigation in spinal fusion surgery. Meanwhile, the technique of navigated pedicle screw placement has become a clinical standard in all involved fields [1-7]. Multiple studies including systematic reviews and meta-analyses have shown a significantly lower risk of pedicle screw malpositioning as well

\section{Bernhard Meyer}

Bernhard.Meyer@tum.de

1 Department of Neurosurgery, Klinikum rechts der Isar, Technical University of Munich, Germany; School of Medicine, Ismaninger Str. 22, 81675 Munich, Germany

2 TUM Neuroimaging Center, Technical University of Munich, Germany, Ismaninger Str. 22, 81675 Munich, Germany 
as a higher accuracy and safety for the navigation-based insertion than for free-hand technique or 2D fluoroscopy [6, 8-12]. The intraoperative acquisition of CT images uses two different types of beams: standard CT scanners with fan-shaped X-ray beams have to be separated from mobile cone-beam CT (CBCT). Hence, multiple imaging solutions especially for mobile CBCT-based approaches but also for mobile CT scanners have been developed which mainly differ regarding the field of view (FOV), imaging quality particularly of soft tissue, their compatibility with navigation platforms, and not at least the acquisition and running costs. Recently, a review on assistive active and passive technologies comprehensively summarized current tools for spine surgery. Obviously, the authors recommended the acquisition of devices with a maximum compatibility and universal registration mechanisms. Moreover, CBCT was described as the technique required for speed, operating efficiency, and mobility. In contrast, mobile CT scanners were recommended for the imaging of long constructs, patients with a high body-mass-index, and cervicothoracic fusion [13]. In addition to these mobile $\mathrm{CT}$ scanner solutions, permanently in the operating room (OR)-installed CT scanners (ORCT) meanwhile using a sliding gantry exist $[7,14,15]$. Although the solution of an ORCT has recently been described as a scarcely used technique in neurosurgery [16], it offers the potential to be efficient for navigated spinal instrumentation alone in a high-volume neurosurgical university center.

The aim of the present study was to analyze the efficiency of an ORCT-based as compared to a mobile CBCT-based approach for spinal instrumentation in a single high-volume neurosurgical center with regard to clinical and resource implications.

\section{Methods}

\section{Ethics}

The study was approved by the local ethics board (registration number: 159/16S). The study was performed in accordance with the Declaration of Helsinki.

\section{Patients}

We retrospectively analyzed all patients who underwent ORCT-based or CBCT-based pedicle screw placement for spinal instrumentation at our department between 11/2015 and 01/2020 independent from the indication. The CBCTbased device and navigation (O-arm; Medtronic Stealth, Medtronic, Minneapolis, Minnesota, USA) was available during the entire study period from November 2015 until January 2020, while the ORCT (Brilliance CT Big Bore, Philips, Amsterdam, Netherlands) combined with Curve
Navigation (Brainlab, AG Munich, Germany) was available from March 2018. During the period with both systems being available, surgeries with navigated pedicle screw placement were scheduled for the use of ORCT or CBCT depending on the departments' organizational concerns. Patients who underwent non-navigated or navigated pedicle screw placement with other devices were not included in the present analysis.

\section{Intraoperative procedures and imaging technologies}

\section{Intraoperative procedures}

All surgeries were performed by a team of seven neurosurgeons who did only change by one person over the course of the study period. All preparing procedures by anesthesiologists were performed in a separate room, hence, the positioning of the patient could start directly after entering the OR. Patients of the present cohort underwent navigated pedicle screw placement by an open midline approach or percutaneous pedicle screw implantation depending on the additional need of decompression or length of construct. The reference array was attached to a spinous process. As a next step, the navigation scan was performed by the according imaging system. During image acquisition, surgeons and nurses were outside the OR. After the automatic transfer of the navigation data set to the navigation software, image quality and compliance with anatomical structures were reviewed. Then, the screw entry point and the trajectory were planned with a navigated drill guide. After drilling with a battery-powered drill, a blunt K-wire was inserted via the drill guide. Finally, cannulated pedicle screws were passed over the K-wire. After placement of all pedicle screws as indicated, a second navigation scan was performed for the review of pedicle screw accuracy by the responsible surgeon.

\section{Mobile cone-beam CT}

For CBCT-based navigated pedicle screw placement, we used the O-arm II (Medtronic, Minneapolis, Minnesota, USA). After positioning and sterile draping of the patient, the gantry (inner width $96.5 \mathrm{~cm}$ ) was draped and placed over the patient and the radiolucent operating table. This was done from lateral by opening the gantry. After closing the gantry and positioning of the navigation system (Medtronic Stealth ${ }^{\text {TM }}$ S7, Medtronic, Minneapolis, Minnesota, USA), a.p. and lateral X-rays were taken for the optimal positioning of the gantry. The position was saved, and the gantry was then transferred to parking position. Preparation and attachment of the reference array as well as navigation and control scans were performed as described above. After the last control scan, decompression if indicated, and skin closure, 
the gantry was opened for the removal of the device and the de-positioning of the patient.

\section{OR-based sliding gantry CT}

For ORCT-based surgeries a Brilliance CT Big Bore (Philips, Amsterdam, Netherlands) with an inner diameter of $85 \mathrm{~cm}$ combined with a ceiling-mounted curve navigation (Brainlab, Munich, Germany) was installed in a newly built OR as a floor-based sliding gantry. The sliding gantry enables a total mobility of $4.5 \mathrm{~m}$. Patients who underwent navigated pedicle screw placement using the ORCT-based approach were similarly positioned and draped as for CBCT. Yet the patient and not the gantry are draped for scanning. The skin incision was planned based on palpation of anatomical structures or C-arm a.p. and lateral X-rays in specific cases. After attaching the reference array and reference matrix as well as an additional sterile draping of the patient, the CT scanner was brought from the parking position over the patient to the end of the sliding gantry in order to review the position of the patient inside the gantry. Then, the navigation and control scans were started and reviewed by a certified radiological CT technician. Finally, the CT scanner was moved to the parking position and surgical procedures were continued after removal of the additional sterile draping.

\section{Data analysis}

In order to compare the two imaging technologies, data on baseline characteristics, surgical details and the course of surgery, accuracy of screw placement and revision rates were collected for all patients who underwent ORCT- or CBCTbased pedicle screw placement during the analyzed period. The latter was rated according to Gertzbein-Robbins classification (Grade $\mathrm{A}=$ breach distance $0 \mathrm{~mm}, \mathrm{~B}=<2 \mathrm{~mm}$, $\mathrm{C}=<4 \mathrm{~mm}, \mathrm{D}=<6 \mathrm{~mm}, \mathrm{E}=>6 \mathrm{~mm}$ ) [17]. Finally, screw placement was separated into sufficient (= clinically ok and solid implantation + strong construct + no neurological compression suspected, usually Gertzbein-Robbins grade $\mathrm{A}+\mathrm{B}+\mathrm{C}$ ) and insufficient. Based on this separation, indications for revision of screws were made intraoperatively. Furthermore, we analyzed data on intra- and postoperative complication rates, further surgeries, and inpatient stay for both groups. For the analysis of the efficiency with regard to clinical (duration of surgery) and economical (utilization of the OR) aspects, we defined different intervals in order to differentiate between time required for the surgery per se and time required for operations which are also associated with the navigation technology:
- Interval 1 Entry-Positioning: Entry of the anesthetized patient into the OR until the completion of patient positioning

- Interval 2 Positioning-Incision: After the completion of patient positioning until skin incision and start of surgery

- Interval 3 Incision-Suture: Skin incision and start of surgery until skin closure and end of surgery

- Interval 4 Suture-Exit: After completed skin closure until the exit of the awake patient from the OR

- Interval 5 Entry-Exit: Time the patient spent inside the OR; according to the sum of intervals 1-4.

All statistical analyses were performed using GraphPad Prism software (GraphPad Prism 8, San Diego, CA, USA). The results of the two groups were compared using independent $t$ tests and Fisher's exact or Chi-square test. A p-value of less than 0.05 was considered significant. Initially, Gaussian distribution was tested for all measures.

\section{Results}

This cohort study included a random sample of 853 patients. The inclusion of this random sample was based on the availability of devices and the scheduling due to organizational concerns. Apart from age, baseline characteristics, duration of inpatient stay, and complication rates did not differ significantly between the two groups (Table 1-3). Patients in the ORCT group underwent more often cervical pedicle screw placement $(18.5 \%$ vs. $7.0 \% ; p<0.0001)$ than patients in the CBCT group (Table 1). Table 1 gives a detailed overview on baseline characteristics and pathologies which indicated spinal instrumentation.

The median and total number of navigated screws the median and total number of instrumented levels did not differ significantly. The number of patients who additionally underwent decompression did not differ between the groups but the number of decompressed levels per surgery was significantly higher in the CBCT group (ORCT: median 1 , range $0-8$ vs. CBCT: $2,0-8 \mathrm{p}=0.0275$ ). Supplemental Digital Content Table 1 summarizes details on numbers of screws, used systems, additional $360^{\circ}$ instrumentation, and decompression.

Intra- and postoperative complications did not differ between groups. Although accuracy of screw placement according to Gertzbein-Robbins classification did not differ between groups, more screws had to be revised intraoperatively in the CBCT group (ORCT: $98,2.8 \%$ vs. CBCT: $128,4.0 \% ; \mathrm{p}=0.0081$ ) based on the intraoperative rating of insufficient screw placement (sufficient $=$ clinically ok and solid implantation + strong construct + no 
Table 1 Baseline characteristics

\begin{tabular}{|c|c|c|c|c|c|}
\hline & & Total & ORCT & $\mathrm{CBCT}$ & $p$-value \\
\hline Period & & Nov 2015-Jan 2020 & Mar 2018-Jan 2020 & Nov 2015-Jan 2020 & \\
\hline Months & & 51 & 23 & 51 & \\
\hline Patients $(n, \%)$ & & $853(100)$ & $439(51.5)$ & $414(48.5)$ & \\
\hline Male $(n, \%)$ & & $492(57.7)$ & $260(59.2)$ & $232(56.0)$ & 0.3676 \\
\hline Female $(n, \%)$ & & $361(42.3)$ & $179(40.8)$ & $182(44.0)$ & \\
\hline Age (mean \pm standard deviation) & & $67.1(14.2)$ & $68.1(13.8)$ & $66.0(14.5)$ & 0.0297 \\
\hline \multirow[t]{5}{*}{ Pathology $(n, \%)$} & Cancer & $289(33.9)$ & $155(35.2)$ & $134(32.4)$ & 0.2534 \\
\hline & Degenerative & $266(31.2)$ & $134(30.5)$ & $132(31.9)$ & \\
\hline & Trauma & $163(19.1)$ & $84(19.1)$ & $79(19.1)$ & \\
\hline & Infection & $131(15.4)$ & $62(14.1)$ & $69(16.7)$ & \\
\hline & Deformity & $4(0.5)$ & $4(0.9)$ & $0(0)$ & \\
\hline Cervical + Cervicothoracic (n, \%) & & $110(12.9)$ & $81(18.5)$ & $29(7.1)$ & $<0.0001$ \\
\hline Thoracic_Lumbar-Sacral—Pelvic $(n, \%)$ & & $743(87.1)$ & $358(81.5)$ & $385(92.9)$ & \\
\hline
\end{tabular}

The table shows baseline characteristics for the whole cohort as well as for the comparison between operating room (OR)-based sliding gantry $\mathrm{CT}(\mathrm{ORCT})$ and mobile cone-beam CT (CBCT) pedicle screw placements

Table 2 Intra- and postoperative complications

\begin{tabular}{|c|c|c|c|c|c|}
\hline & & Total & ORCT & CBCT & $p$-value \\
\hline \multirow{2}{*}{$\begin{array}{l}\text { Revised screws } \\
(n, \%)\end{array}$} & Total & $226(3.4)$ & $98(2.8)$ & $128(4.0)$ & 0.0081 \\
\hline & Cases & $143(16.8)$ & $66(15.0)$ & 77 (18.6) & 0.17 \\
\hline \multirow[t]{2}{*}{ Revised screws-multiple $(n, \%)$} & Total & $21(9.3)$ & $12(12.2)$ & $9(7.0)$ & 0.3567 \\
\hline & Cases & $18(12.6)$ & $10(15.2)$ & $8(10.4)$ & 0.6173 \\
\hline \multirow{3}{*}{$\begin{array}{l}\text { Intraoperative complications } \\
(n, \%)\end{array}$} & None & $806(94.5)$ & $412(93.8)$ & $394(95.2)$ & 0.1957 \\
\hline & Technical & $18(2.1)$ & $13(3.0)$ & $5(1.2)$ & \\
\hline & Medical & $29(3.4)$ & $14(3.2)$ & $15(3.6)$ & \\
\hline \multirow{9}{*}{$\begin{array}{l}\text { Postoperative complications } \\
(n, \%)\end{array}$} & Total & $160(18.8)$ & $80(18.2)$ & $80(19.3)$ & 0.5721 \\
\hline & Surgery & $36(4.2)$ & $15(4.8)$ & $21(4.8)$ & \\
\hline & Lung & $27(3.2)$ & $13(3.2)$ & $14(3.2)$ & \\
\hline & Died & $22(2.6)$ & $10(2.7)$ & $12(2.8)$ & \\
\hline & Wound & $21(2.5)$ & $12(2.1)$ & $9(2.1)$ & \\
\hline & Vigilance & $19(2.2)$ & $8(2.5)$ & $11(2.5)$ & \\
\hline & Medical & $19(2.2)$ & $13(1.4)$ & $6(1.4)$ & \\
\hline & Heart & $13(1.5)$ & $8(1.1)$ & $5(1.2)$ & \\
\hline & Vascular & $3(0.4)$ & $1(0.5)$ & $2(0.5)$ & \\
\hline \multirow[t]{2}{*}{ Postoperative hospitalization (days) } & Median & 15 & 14 & 15 & 0.2174 \\
\hline & {$[95 \% \mathrm{CI}]$} & {$[17.3,19.2]$} & {$[16.5,19.1]$} & {$[17.3,20.1]$} & \\
\hline
\end{tabular}

The table shows details on intra- and postoperative complications as well as revision rates based on the accuracy of screw placement and the duration of hospitalization between operating room intraoperative computed tomography (ORCT)-based and cone-beam intraoperative computed tomography (CBCT)-based pedicle screw placements. Indication for revision was made in case of insufficient screw placement (Sufficient $=$ clinically ok and solid implantation + strong construct + no neurological compression suspected (Gertzbein-Robbins grade A $+B+C$ ), Insufficient=indication for revision of the screw, Technical=delay due to any problem with technical equipment, Medical=complications related to the intraoperative status of the patient, e.g., blood pressure, respiration) neurological compression suspected [Gertzbein-Robbins grade $\mathrm{A}+\mathrm{B}+\mathrm{C}]$ ). Important to note that there was no case in this consecutive series which had to be taken back to the
OR due to required replacement of any pedicle screws. Figures 1 and 2 show illustrative cases of navigation and control scans for instrumentation of vertebra C7 (Fig. 1) and L4 
Table 3 Intervals

\begin{tabular}{llllll}
\hline & & Total & ORCT & CBCT & $p$-value \\
\hline Interval 1 & Mean & 20.3 & 19.8 & 20.8 & 0.3375 \\
Entry_Positioning (min) & {$[95 \% \mathrm{CI}]$} & {$[19.3,21.3]$} & {$[18.4,21.3]$} & {$[19.3,22.2]$} & \\
Interval 2 & Mean & 26.1 & 18.8 & 33.6 & $<0.0001$ \\
Positioning_Incision (min) & {$[95 \% \mathrm{CI}]$} & {$[25.2,27.3]$} & {$[18.1,19.9]$} & {$[32.2,35.5]$} & \\
Interval 3 & Mean & 199.6 & 196.1 & 203.3 & 0.1363 \\
Incision_Suture (min) & {$[95 \% \mathrm{CI}]$} & {$[191.7,205.0]$} & {$[188.8,203.4]$} & {$[195.3,211.3]$} & \\
Interval 4 & Mean & 26.7 & 24.3 & 29.3 & $<0.0001$ \\
Suture-Exit (min) & {$[95 \% \mathrm{CI}]$} & {$[25.9,28.0]$} & {$[23.6,26.1]$} & {$[27.5,30.7]$} & \\
Interval 5 & Mean & 269.2 & 256.0 & 283.0 & $<0.0001$ \\
Entry_Exit (min) & {$[95 \% \mathrm{CI}]$} & {$[263.2,275.2]$} & {$[247.8,264.3]$} & {$[274.4,291.5]$} & \\
\hline
\end{tabular}

The table shows details on intervals the patients have spent inside the operating room (OR) for OR-based sliding gantry CT (ORCT) and mobile cone-beam CT (CBCT) pedicle screw placements (Interval 1 Entry-Positioning: Entry of the anesthetized patient into the OR until the completion of patient positioning, Interval 2 Positioning-Incision: After the completion of patient positioning until skin incision and start of surgery, Interval 3 Incision-Suture: Skin incision and start of surgery until skin closure and end of surgery, Interval 4 Suture-Exit: After completed skin closure until the exit of the awake patient from the OR, Interval 5 Entry-Exit: Time the patient spend inside the OR; according to the sum of intervals 1-4)

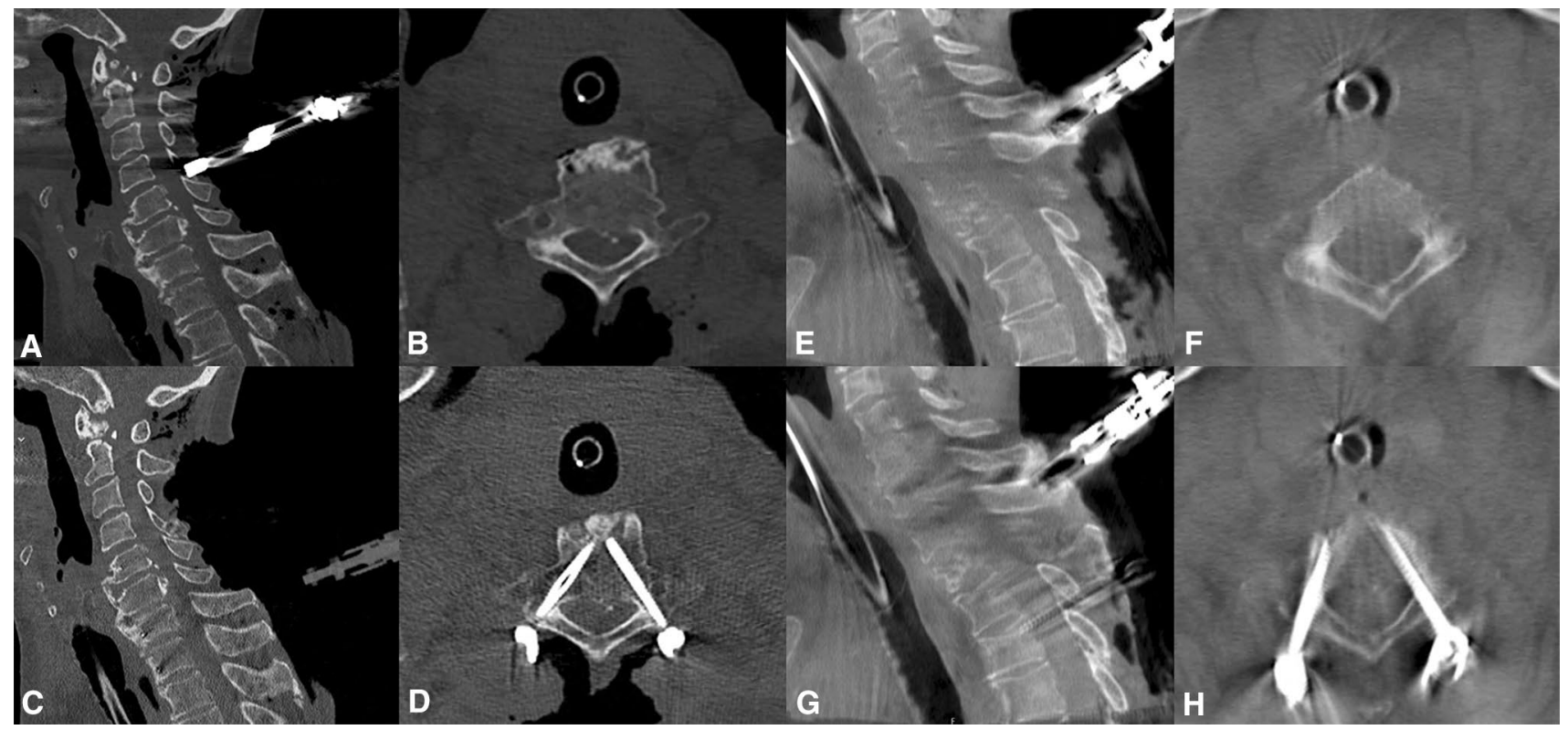

Fig. 1 Pedicle screw placement in vertebra C7 The figure shows two different illustrative cases of navigation and control scans for instrumentation of vertebra $\mathrm{C} 7$ using operating room (OR)-based sliding

(Fig. 2) using ORCT or CBCT. Table 2 shows overall data regarding intra- and postoperative complications, accuracy of screw placement according to Gertzbein-Robbins classification, revisions, and the duration of inpatient stay. gantry CT (ORCT, A-D) and mobile cone-beam CT (CBCT, E-H). Panels show intraoperative sagittal and axial slices before $(\mathbf{A}, \mathbf{B}, \mathbf{E}$, $\mathbf{F})$ and after $(\mathbf{C}, \mathbf{D}, \mathbf{G}, \mathbf{H})$ rigid pedicle screw instrumentation

The mean time of patients inside the OR (Interval 5 Entry-Exit) was significantly shorter for the ORCT group (ORCT: mean, [95\% CI] 256.0, [247.8, 264.3] min, CBCT: 283.0, [274.4, 291.5] min; p < 0.0001) based on shorter 


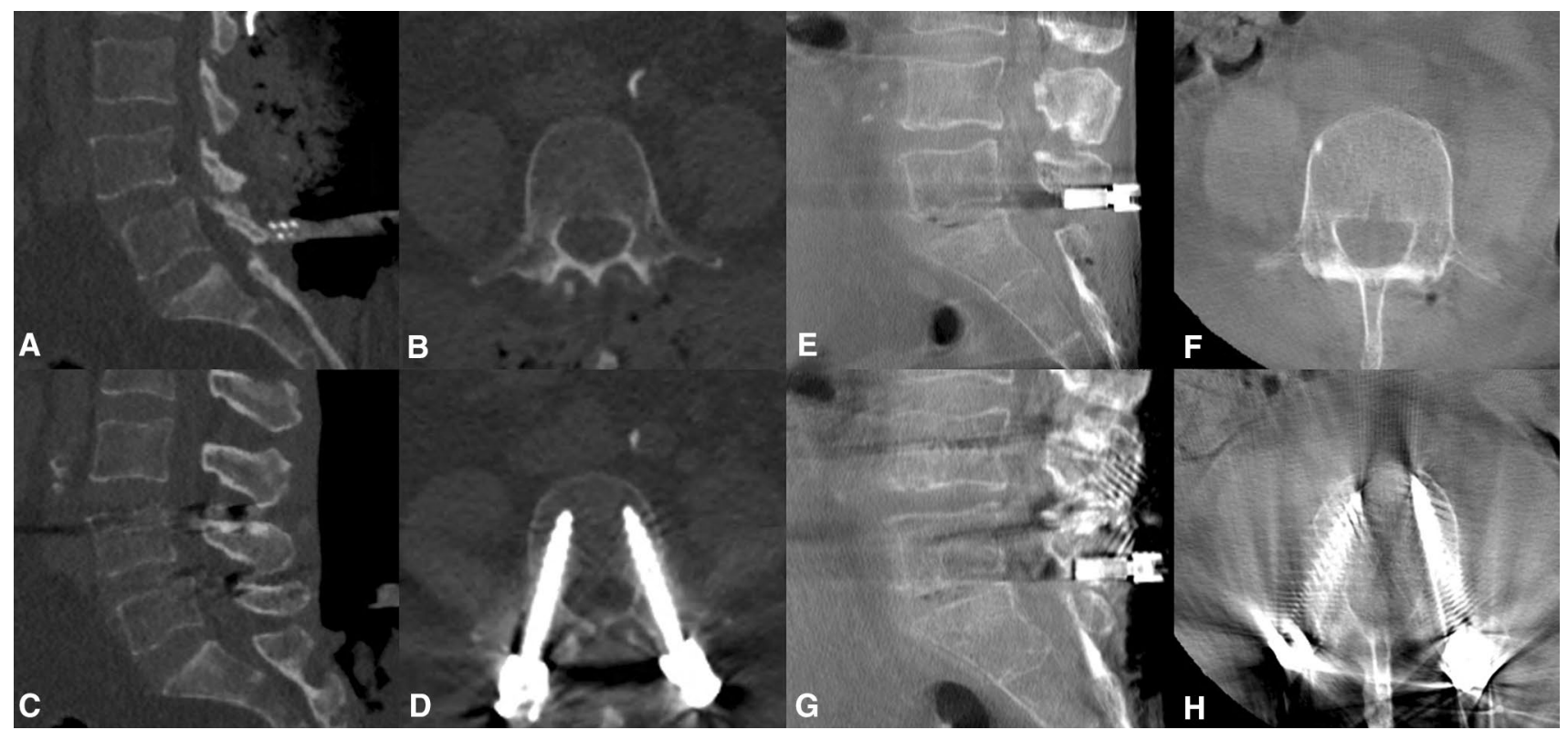

Fig. 2 Pedicle screw placement in vertebra L4 The figure shows two different illustrative cases of navigation and control scans for instrumentation of vertebra L4 using operating room (OR)-based sliding

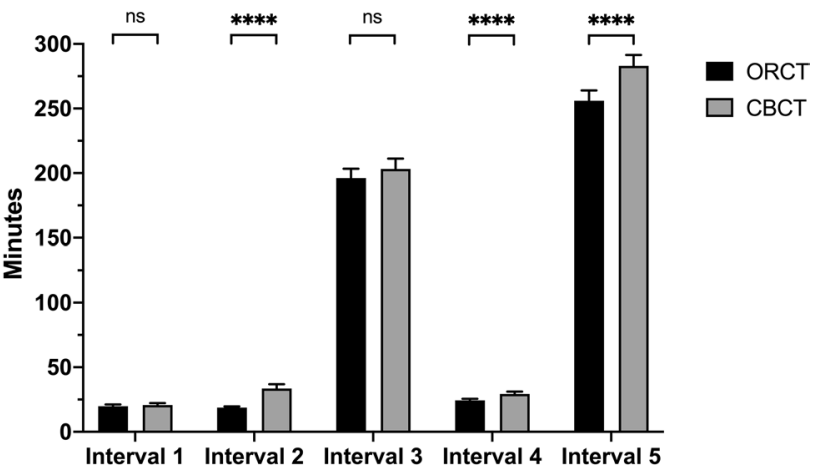

Fig. 3 Intervals The figure shows means with 95\% CI durations for Interval 1 Entry-Positioning (entry of the anesthetized patient into the operating room (OR) until the completion of patient positioning), Interval 2 Positioning-Incision (after the completion of patient positioning until skin incision and start of surgery), Interval 3 IncisionSuture (skin incision and start of surgery until skin closure and end of surgery), Interval 4 Suture-Exit (after completed skin closure until the exit of the awake patient from the OR), and Interval 5 EntryExit (time the patient spent inside the OR; according to the sum of intervals $1-4)$ for OR-based sliding gantry CT (ORCT) and mobile cone-beam CT (CBCT) pedicle screw placements (ns=not significant, $* * * *=p<0.0001)$

times for Interval 2 Positioning-Incision (ORCT: 18.8, [18.1, 19.9] min, CBCT: 33.6, [32.2, 35.5] min; $\mathrm{p}<0.0001)$ and Interval 4 Suture -Exit (ORCT: 24.3, [23.6, 26.1] min, CBCT: 29.3, [27.5, 30.7] min; $p<0.0001)$. Figure 3 and Table 3 show means and 95\% CI for Interval 1-5. Figure 4 and Table 4 show single durations for Interval 1-5 of gantry CT (ORCT, A-D) and mobile cone-beam CT (CBCT, E-H). Panels show intraoperative sagittal and axial slices before $(\mathbf{A}, \mathbf{B}, \mathbf{E}$, $\mathbf{F})$ and after $(\mathbf{C}, \mathbf{D}, \mathbf{G}, \mathbf{H})$ rigid pedicle screw instrumentation

patients who underwent cervicothoracic or thoracolumbar instrumentation.

\section{Discussion}

\section{Efficiency of OR-based sliding gantry CT}

The present study's analysis shows that the ORCT-based navigated placement of pedicle screws is more efficient than the CBCT-based with regard to duration of OR use and thereby resource implications (Table 3 and Table 4). The analysis of this very homogenous cohort as shown by baseline characteristics and surgical details (Table 1 and 2) proves the effect of an optimized OR equipped with a permanently installed ioCT with sliding gantry on standard spine surgery procedures in a high-volume tertiary care center. The significant difference of the patients' presence in the OR (Interval 5 Entry-Exit) was significantly shorter for the ORCT group mainly base on the significantly shorter duration needed for preparing the positioned patient for the ioCT-based imaging and to a lesser extent on shorter times needed for the de-positioning of the patient (Fig. 3). As the detailed illustration for all intervals and the analysis of durations per level shows, durations of the CBCT group are more heterogeneously distributed in comparison with the ORCT group (Fig. 4 and Table 4). With regard to the validity of the present data, surgical procedures as recorded by Interval 3 Incision-Suture did 
not affect these differences. Of course, the time needed for imaging-based preparations in the CBCT group is included in Interval 2 Positioning-Incision, while preparations for ioCT imaging in the ORCT group count among Interval 3 Incision-Suture due to performing CT scout images for scan and radiation dose planning. The still missing difference for Interval 3 Incision-Suture should preliminary be reasoned by the higher number of scans which had to be performed for a higher number of levels in CBCT cases as compared to ORCT cases which can be done with one scan prior and one scan after all screws were placed. Additionally, it might also be reasoned by the higher number of levels decompressed in patients of the CBCT group. However, the number of cases which underwent decompression did not differ between groups, hence, the impact of this time-consuming intraoperative procedure included in Interval 3 Incision-Suture has less impact on the overall results (Table 2 and Table 4). Furthermore, the familiarity of handling the devices and particularly the preparation as well as de-positioning should have affected Interval 2 Positioning-Incision and Interval 4 Suture-Exit. However, we included patients to the two groups from the beginning of their availability at our department, respectively. Hence, the learning curves for the handling and preparation are included for both devices.

While the results could also be shown after the separation into instrumentations of cervicothoracic or thoracolumbar levels, we additionally found shorter durations for Interval 1 Entry-Positioning and Interval 3 Incision-Suture for the cervicothoracic subgroup. Furthermore, the analysis per level did not show significant differences (Table 4 and Fig. 4). This might be reasoned by the higher percentage of cervicothoracic cases in the ORCT group (Table 1).

At our department, we standardly perform at least two intraoperative scans for navigation and control of pedicle screws. This offers the possibility for an immediate intraoperative revision of screws based on a navigational intraoperative scan. It has to be mentioned that centers exist which only perform a navigation scan without a standard control scan. Of course, this is reasonable from a practical point of view. However, regarding the radiation exposure of patients and the surgical team, an earlier randomized controlled trial could show that the cumulative radiation dose of the procedure as performed in the present study is acceptable and even lower as compared to 2D-fluoroscopy-guided free-hand instrumentations [18].

Clinically, screws had to be revised less frequently in the ORCT group as compared to the CBCT group, while the accuracy of screw placement according to Gertzbein-Robbins classification showed no significant differences between the two groups (Table 3). Based on the results of the present study and personal experience, higher revision rates in the CBCT group are reasoned by an inferior visualization as compared to an ORCT-based spinal instrumentation (Fig. 1 and 2). Moreover, the revision of misplaced screws seems to be faster by the help of CBCT decreasing the threshold for revision in uncertain cases. Due to the retrospective character of the present study, this assumption cannot be supported by hard numbers though.

Apart from these comparisons of ORCT and CBCT focusing the durations of perioperative intervals, imaging quality, and accuracy of instrumentation, the two devices still have advantages and disadvantages. The CBCT device enables to perform the intraoperative imaging without dependence on radiologists and technical assistants as it is necessary for the ORCT device. This fact might be timeconsuming and error-prone in case of not well-attuned teams. Otherwise, the ORCT device offers the opportunity to image multiple levels as defined by the surgeon. In contrast, the imaging of the CBCT device is limited to several vertebrae. This might be negligible in case of standard instrumentations including up to 5 levels but is a factor for longer constructs.

\section{ioCT-based pedicle screw placement}

Former publications have already shown a significantly lower risk of pedicle screw malpositioning as well as a higher accuracy and safety for the intraoperative CT (ioCT)navigated insertion than for free-hand technique or 2D fluoroscopy [6, 8-12]. Several studies have investigated the use of mobile ioCT scanners [1, 19-22] In contrast to publications on CBCT-based pedicle screw placement, reports on the use of permanently installed ORCTs are scarce [7, 14-16]. While the accuracy of pedicle screw placement and revision rates of the present study are comparable to earlier publications on navigated pedicle screws, the differences of durations are difficult to compare since measurements, subgroups, and the complexity of surgeries vary across publications. With a special regard to instrumentation of the cervical spine and cervicothoracic junction, the present study's results show one of the largest cohorts with CT-navigated cervical pedicle screws [23-26]. The present subanalysis showed less differences for the comparison of the ORCT and CBCT group. Apart from that we could prove the results of an earlier large cohort study showing now the safety of CT-navigated instrumentation of this region [26]. In the present cohort, patients in the ORCT group underwent more often cervical pedicle screw placement $(18.5 \%$ vs. $7.0 \% ; p<0.0001$ ) than patients in the CBCT group due to the possibility of region matching (Brainlab AG, Munich, Germany; Table 1).

Our analysis also revealed that intraoperative screw evaluation does not take the Gertzbein-Robbins classification into account when it comes to the decision 

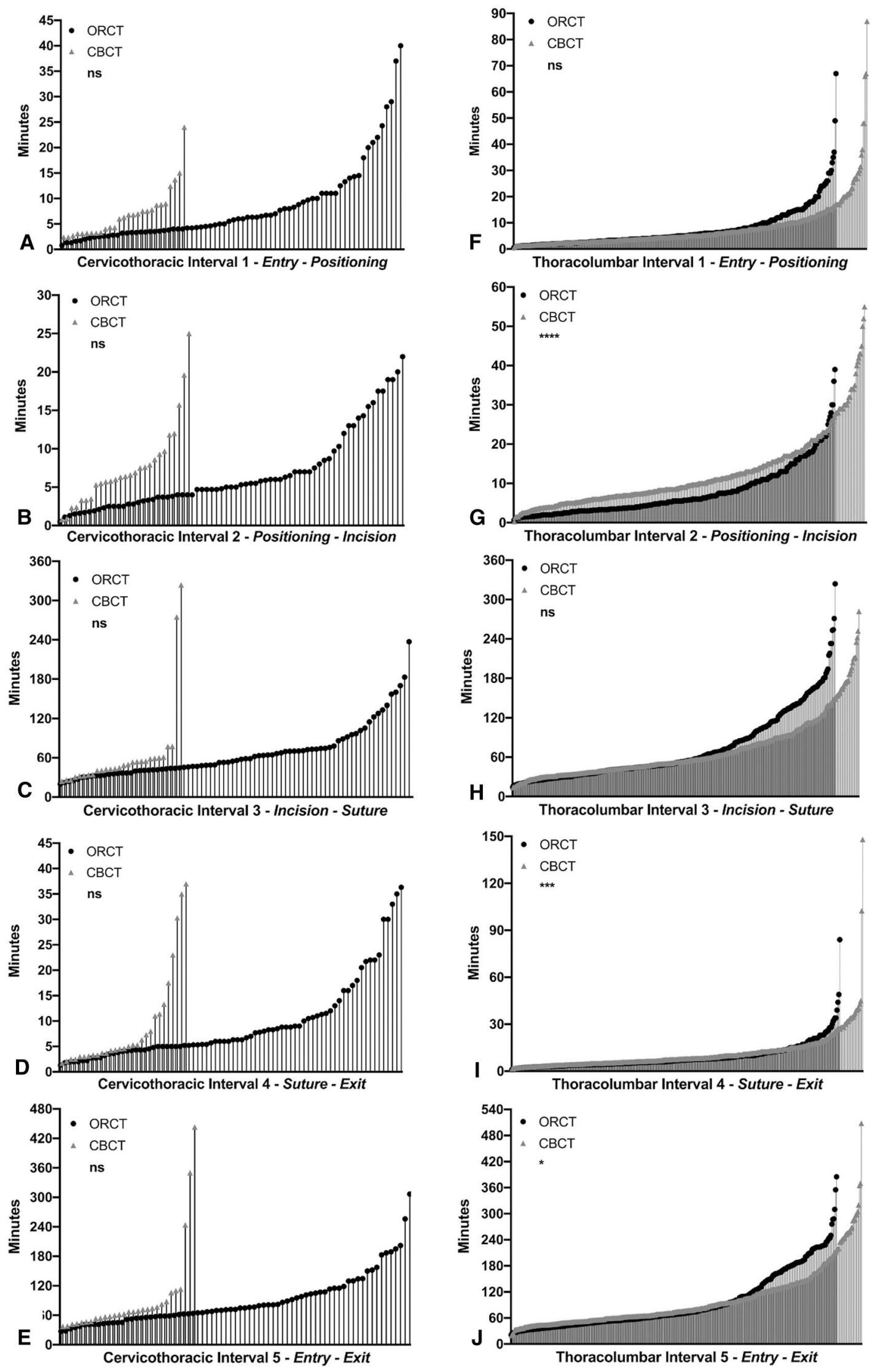
4Fig. 4 Single durations per level The figure shows single durations per level for Interval 1 Entry-Positioning (entry of the anesthetized patient into the operating room (OR) until the completion of patient positioning), Interval 2 Positioning-Incision (after the completion of patient positioning until skin incision and start of surgery), Interval 3 Incision-Suture (skin incision and start of surgery until skin closure and end of surgery), Interval 4 Suture-Exit (after completed skin closure until the exit of the awake patient from the OR), and Interval 5 Entry-Exit (time the patient spent inside the OR; according to the sum of intervals 1-4) for OR-based sliding gantry CT (ORCT, dark gray) and mobile cone-beam CT (CBCT, light gray) pedicle screw placements. The figure separates durations per level for cervicothoracic $(\mathrm{A}-\mathrm{E})$ and thoracolumbar $(\mathrm{F}-\mathrm{J})$ instrumentations (ns not significant, ${ }^{*} p<0.05, * * * p<0.001$, **** $p<0.0001$

of intraoperative screw revision. That is because this decision requires other parameters such as haptic bone quality, screw firmness and anatomical difficulties during placement into direct account. As a result, the Gertzbein-Robbins classification was not used to describe the results since it was not used for intraoperative decision making at all. Important to note that there was no case in this consecutive series which had to be taken back to the OR due to required replacement of any pedicle screws.

\section{Limitations}

The retrospective character of the present analysis might be a major limitation of our study. Hence, the analysis had to be limited to the presented parameters. For example, the learning curve for the two devices was not considered in the analysis. However, these data and especially the main results are based on digitally documented reports and are thereby highly reliable.

Table 4 Cervicothoracic and thoracolumbar intervals

\begin{tabular}{|c|c|c|c|c|c|c|c|}
\hline & & \multicolumn{3}{|l|}{ Overall } & \multicolumn{3}{|l|}{ Per level } \\
\hline & & ORCT & СВCT & $p$ value & ORCT & CBCT & $p$ value \\
\hline \multicolumn{8}{|l|}{ Cervicothoracic } \\
\hline $\begin{array}{l}\text { Interval } 1 \\
\text { Entry—Positioning (min) }\end{array}$ & $\begin{array}{l}\text { Mean } \\
{[95 \% \mathrm{CI}]}\end{array}$ & $\begin{array}{l}23.9 \\
{[20.2,27.7]}\end{array}$ & $\begin{array}{l}27.9 \\
{[23.3,32.5]}\end{array}$ & 0.0197 & $\begin{array}{l}8.4 \\
{[6.5,10.2]}\end{array}$ & $\begin{array}{l}6.9 \\
{[5.0,8.8]}\end{array}$ & 0.8027 \\
\hline $\begin{array}{l}\text { Interval } 2 \\
\text { Positioning_Incision (min) }\end{array}$ & $\begin{array}{l}\text { Mean } \\
{[95 \% \mathrm{CI}]}\end{array}$ & $\begin{array}{l}19.3 \\
{[17.4,21.2]}\end{array}$ & $\begin{array}{l}38.0 \\
{[26.4,49.4]}\end{array}$ & 0.0005 & $\begin{array}{l}7.0 \\
{[5.7,8.3]}\end{array}$ & $\begin{array}{l}7.6 \\
{[5.4,9.8]}\end{array}$ & 0.2504 \\
\hline $\begin{array}{l}\text { Interval } 3 \\
\text { Incision-Suture (min) }\end{array}$ & $\begin{array}{l}\text { Mean } \\
{[95 \% \mathrm{CI}]}\end{array}$ & $\begin{array}{l}210.2 \\
{[191.4,228.9]}\end{array}$ & $\begin{array}{l}256.2 \\
{[219.2,293.2]}\end{array}$ & 0.0084 & $\begin{array}{l}69.3 \\
{[59.2,79.4]}\end{array}$ & $\begin{array}{l}64.4 \\
{[38.0,90.8]}\end{array}$ & 0.0796 \\
\hline $\begin{array}{l}\text { Interval } 4 \\
\text { Suture-Exit (min) }\end{array}$ & $\begin{array}{l}\text { Mean } \\
{[95 \% \mathrm{CI}]}\end{array}$ & $\begin{array}{l}26.2 \\
{[23.2,29.3]}\end{array}$ & $\begin{array}{l}29.6 \\
{[23.5,35.8]}\end{array}$ & 0.3536 & $\begin{array}{l}9.4 \\
{[7.6,11.2]}\end{array}$ & $\begin{array}{l}9.1 \\
{[5.4,12.9]}\end{array}$ & 0.1892 \\
\hline $\begin{array}{l}\text { Interval } 5 \\
\text { Entry-Exit (min) }\end{array}$ & $\begin{array}{l}\text { Mean } \\
{[95 \% \mathrm{CI}]}\end{array}$ & $\begin{array}{l}277.9 \\
{[255.5,300.3]}\end{array}$ & $\begin{array}{l}336.5 \\
{[303.8,369.2]}\end{array}$ & 0.0006 & $\begin{array}{l}89.2 \\
{[77.0,101.3]}\end{array}$ & $\begin{array}{l}94.4 \\
{[59.1,129.8]}\end{array}$ & 0.3471 \\
\hline \multicolumn{8}{|l|}{ Thoracolumbar } \\
\hline $\begin{array}{l}\text { Interval } 1 \\
\text { Entry—Positioning (min) }\end{array}$ & $\begin{array}{l}\text { Mean } \\
{[95 \% \mathrm{CI}]}\end{array}$ & $\begin{array}{l}19.0 \\
{[17.4,20.5]}\end{array}$ & $\begin{array}{l}20.3 \\
{[18.8,21.8]}\end{array}$ & 0.2475 & $\begin{array}{l}7.3 \\
{[6.5,8.1]}\end{array}$ & $\begin{array}{l}7.7 \\
{[6.8,8.6]}\end{array}$ & 0.5720 \\
\hline $\begin{array}{l}\text { Interval } 2 \\
\text { Positioning_Incision (min) }\end{array}$ & $\begin{array}{l}\text { Mean } \\
{[95 \% \mathrm{CI}]}\end{array}$ & $\begin{array}{l}18.7 \\
{[17.7,19.7]}\end{array}$ & $\begin{array}{l}33.4 \\
{[31.8,34.9]}\end{array}$ & $<0.0001$ & $\begin{array}{l}7.5 \\
{[6.8,8.2]}\end{array}$ & $\begin{array}{l}12.3 \\
{[11.4,13.3]}\end{array}$ & $<0.0001$ \\
\hline $\begin{array}{l}\text { Interval } 3 \\
\text { Incision-Suture (min) }\end{array}$ & $\begin{array}{l}\text { Mean } \\
{[95 \% \mathrm{CI}]}\end{array}$ & $\begin{array}{l}192.9 \\
{[185.0,200.8]}\end{array}$ & $\begin{array}{l}199.3 \\
{[191.2,207.4]}\end{array}$ & 0.1881 & $\begin{array}{l}71.9 \\
{[66.6,77.3]}\end{array}$ & $\begin{array}{l}69.8 \\
{[65.1,74.5]}\end{array}$ & 0.5157 \\
\hline $\begin{array}{l}\text { Interval } 4 \\
\text { Suture-Exit (min) }\end{array}$ & $\begin{array}{l}\text { Mean } \\
{[95 \% \mathrm{CI}]}\end{array}$ & $\begin{array}{l}23.9 \\
{[22.6,25.2]}\end{array}$ & $\begin{array}{l}29.3 \\
{[27.4,31.2]}\end{array}$ & $<0.0001$ & $\begin{array}{l}9.0 \\
{[8.1,9.9]}\end{array}$ & $\begin{array}{l}11.1 \\
{[9.9,12.3]}\end{array}$ & 0.0004 \\
\hline $\begin{array}{l}\text { Interval } 5 \\
\text { Entry-Exit (min) }\end{array}$ & $\begin{array}{l}\text { Mean } \\
{[95 \% \mathrm{CI}]}\end{array}$ & $\begin{array}{l}251.3 \\
{[242.6,260.0]}\end{array}$ & $\begin{array}{l}278.8 \\
{[270.1,287.6]}\end{array}$ & $<0.0001$ & $\begin{array}{l}94.3 \\
{[87.4,101.2]}\end{array}$ & $\begin{array}{l}100.0 \\
{[93.3,106.6]}\end{array}$ & 0.0117 \\
\hline
\end{tabular}

The table shows details on intervals the patients have spent within the operating room (Interval 1 Entry-Positioning: Entry of the anesthetized patient into the operating room until the completion of patient positioning, Interval 2 Positioning-Incision: After the completion of patient positioning until skin incision and start of surgery, Interval 3 Incision-Suture: Skin incision and start of surgery until skin closure and end of surgery, Interval 4 Suture - Exit: After completed skin closure until the exit of the awake patient from the operating room, Interval 5 Entry—Exit: Time the patient spend within the operating room; according to the sum of intervals 1-4). Durations are shown as overall and per level as well as for cervicothoracic and thoracolumbar instrumentation 


\section{Conclusion}

The present results show that the choice of imaging technology for navigated pedicle screw placement has significant impact on standard spine procedures even in a highvolume spine center with daily usage of such technology. Particularly, the duration of surgeries, the shorter time needed for preparation and de-positioning in the ORCT group made the main difference, while the accuracy was even higher.

Supplementary Information The online version contains supplementary material available at https://doi.org/10.1007/s00586-021-06981-3.

Authors' contributions Conceptualization was done by Bernhard Meyer and Sandro Krieg. Methodology was done by Bernhard Meyer and Sandro Krieg. Formal analysis and investigation were carried out by Sebastian Ille, Lea Baumgart, and Thomas Obermueller. Writingoriginal draft preparation was carried out by Sebastian Ille. Writingreview and editing was done by Thomas Obermueller, Bernhard Meyer, and Sandro Krieg. Resources were done by Bernhard Meyer. Supervision was done by Bernhard Meyer and Sandro Krieg.

Funding Open Access funding enabled and organized by Projekt DEAL. This research did not receive any specific grant from funding agencies in the public, commercial, or not-for-profit sectors. This trial was funded entirely by institutional grants from the Department of Neurosurgery, Technical University of Munich, Germany, School of Medicine, Klinikum rechts der Isar.

\section{Declarations}

Conflict of interests All authors declare that they have no conflict of interest regarding the materials used or the results presented in this study. All authors declare no other relationships or activities that could appear to have influenced the submitted work. BM received honoraria, consulting fees, and research grants from Medtronic (Meerbusch, Germany), Icotec AG (Altstätten, Switzerland), and Relievant Medsystems Inc., (Sunnyvale, CA, USA), honoraria, and research grants from Ulrich Medical (Ulm, Germany), honoraria and consulting fees from Spineart Deutschland GmbH (Frankfurt, Germany) and DePuy Synthes (West Chester, PA, USA), and royalties from Spineart Deutschland $\mathrm{GmbH}$ (Frankfurt, Germany). SK is consultant for Ulrich medical (Ulm, Germany and Brainlab AG (Munich, Germany) and received honoraria from Nexstim Plc (Helsinki, Finland), Spineart Deutschland GmbH (Frankfurt, Germany), Medtronic (Meerbusch, Germany) and Carl Zeiss Meditec (Oberkochen, Germany). BM received research grants and is consultant for Brainlab AG (Munich, Germany). SI is consultant for Brainlab AG (Munich, Germany). All authors declare that they have no conflict of interest regarding the materials used or the results presented in this study. This research did not receive any specific grant from funding agencies in the public, commercial, or notfor-profit sectors. This trial was funded entirely by institutional grants from the Department of Neurosurgery, Technical University of Munich, Germany, School of Medicine, Klinikum rechts der Isar.

Ethics approval The study was approved by the local ethics board (registration number: 159/16S). The study was performed in accordance with the Declaration of Helsinki.

Data availability The data presented in this study are available on request from the corresponding author.
Open Access This article is licensed under a Creative Commons Attribution 4.0 International License, which permits use, sharing, adaptation, distribution and reproduction in any medium or format, as long as you give appropriate credit to the original author(s) and the source, provide a link to the Creative Commons licence, and indicate if changes were made. The images or other third party material in this article are included in the article's Creative Commons licence, unless indicated otherwise in a credit line to the material. If material is not included in the article's Creative Commons licence and your intended use is not permitted by statutory regulation or exceeds the permitted use, you will need to obtain permission directly from the copyright holder. To view a copy of this licence, visit http://creativecommons.org/licenses/by/4.0/.

\section{References}

1. Hecht N, Yassin H, Czabanka M, Föhre B, Arden K, Liebig T, Vajkoczy P (2018) Intraoperative Computed Tomography Versus 3D C-Arm Imaging for Navigated Spinal Instrumentation. Spine (Phila Pa 1976) 43:370-377. https://doi.org/10.1097/brs.00000 00000002173

2. Laine T, Lund T, Ylikoski M, Lohikoski J, Schlenzka D (2000) Accuracy of pedicle screw insertion with and without computer assistance: a randomised controlled clinical study in 100 consecutive patients. Eur Spine J 9:235-240. https://doi.org/10.1007/ s005860000146

3. Richter M, Mattes T, Cakir B (2004) Computer-assisted posterior instrumentation of the cervical and cervico-thoracic spine. Eur Spine J 13:50-59. https://doi.org/10.1007/s00586-003-0604-1

4. Richter M, Cakir B, Schmidt R (2005) Cervical pedicle screws: conventional versus computer-assisted placement of cannulated screws. Spine (Phila Pa 1976) 30:2280-2287. doi: https://doi.org/ 10.1097/01.brs.0000182275.31425.cd

5. Rivkin MA, Yocom SS (2014) Thoracolumbar instrumentation with CT-guided navigation $(\mathrm{O}-\mathrm{arm})$ in 270 consecutive patients: accuracy rates and lessons learned. Neurosurg Focus 36:E7. https://doi.org/10.3171/2014.1.Focus 13499

6. Waschke A, Walter J, Duenisch P, Reichart R, Kalff R, Ewald C (2013) CT-navigation versus fluoroscopy-guided placement of pedicle screws at the thoracolumbar spine: single center experience of 4,500 screws. Eur Spine J 22:654-660. https://doi.org/10. 1007/s00586-012-2509-3

7. Zausinger S, Scheder B, Uhl E, Heigl T, Morhard D, Tonn JC (2009) Intraoperative computed tomography with integrated navigation system in spinal stabilizations. Spine (Phila Pa 1976) 34:2919-2926. doi: https://doi.org/10.1097/BRS.0b013e3181 b77b19

8. Gelalis ID, Paschos NK, Pakos EE, Politis AN, Arnaoutoglou CM, Karageorgos AC, Ploumis A, Xenakis TA (2012) Accuracy of pedicle screw placement: a systematic review of prospective in vivo studies comparing free hand, fluoroscopy guidance and navigation techniques. Eur Spine J 21:247-255. https://doi.org/ 10.1007/s00586-011-2011-3

9. Shin BJ, James AR, Njoku IU, Härtl R (2012) Pedicle screw navigation: a systematic review and meta-analysis of perforation risk for computer-navigated versus freehand insertion. J Neurosurg Spine 17:113-122. https://doi.org/10.3171/2012.5.Spine11399

10. Innocenzi G, Bistazzoni S, D'Ercole M, Cardarelli G, Ricciardi F (2017) Does Navigation Improve Pedicle Screw Placement Accuracy? Comparison Between Navigated and Non-navigated Percutaneous and Open Fixations. Acta Neurochir Suppl 124:289-295. https://doi.org/10.1007/978-3-319-39546-3_42

11. Meng XT, Guan XF, Zhang HL, He SS (2016) Computer navigation versus fluoroscopy-guided navigation for thoracic pedicle 
screw placement: a meta-analysis. Neurosurg Rev 39:385-391. https://doi.org/10.1007/s10143-015-0679-2

12. Shin MH, Hur JW, Ryu KS, Park CK (2015) Prospective comparison study between the fluoroscopy-guided and navigation coupled with $\mathrm{O}$-arm-guided pedicle screw placement in the thoracic and lumbosacral Spines. J Spinal Disord Tech 28:E347-351. https:// doi.org/10.1097/BSD.0b013e31829047a7

13. Malham GM, Wells-Quinn T (2019) What should my hospital buy next?-Guidelines for the acquisition and application of imaging, navigation, and robotics for spine surgery. J Spine Surg 5:155165. https://doi.org/10.21037/jss.2019.02.04

14. Uhl E, Zausinger S, Morhard D, Heigl T, Scheder B, Rachinger W, Schichor C, Tonn JC (2009) Intraoperative computed tomography with integrated navigation system in a multidisciplinary operating suite. Neurosurgery 64:231-239; discussion 239-240. doi: https:// doi.org/10.1227/01.Neu.0000340785.51492.B5

15. Tormenti MJ, Kostov DB, Gardner PA, Kanter AS, Spiro RM, Okonkwo DO (2010) Intraoperative computed tomography imageguided navigation for posterior thoracolumbar spinal instrumentation in spinal deformity surgery. Neurosurg Focus 28:E11. https:// doi.org/10.3171/2010.1.Focus09275

16. Lenski M, Hofereiter J, Terpolilli N, Sandner T, Zausinger S, Tonn JC, Kreth FW, Schichor C (2019) Dual-room CT with a sliding gantry for intraoperative imaging: feasibility and workflow analysis of an interdisciplinary concept. Int J Comput Assist Radiol Surg 14:397-407. https://doi.org/10.1007/s11548-018-1812-9

17. Gertzbein SD, Robbins SE (1990) Accuracy of pedicular screw placement in vivo. Spine (Phila Pa 1976) 15:11-14. doi: https:// doi.org/10.1097/00007632-199001000-00004

18. Villard J, Ryang YM, Demetriades AK, Reinke A, Behr M, Preuss A, Meyer B, Ringel F (2014) Radiation exposure to the surgeon and the patient during posterior lumbar spinal instrumentation: a prospective randomized comparison of navigated versus non-navigated freehand techniques. Spine (Phila Pa 1976) 39:1004-1009. doi: https://doi.org/10.1097/brs.0000000000000351

19. Scarone P, Vincenzo G, Distefano D, Del Grande F, Cianfoni A, Presilla S, Reinert M (2018) Use of the Airo mobile intraoperative $\mathrm{CT}$ system versus the $\mathrm{O}$-arm for transpedicular screw fixation in the thoracic and lumbar spine: a retrospective cohort study of 263 patients. J Neurosurg Spine 29:397-406. https://doi.org/10.3171/ 2018.1.Spine 17927

20. Farah K, Coudert P, Graillon T, Blondel B, Dufour H, Gille O, Fuentes S (2018) Prospective Comparative Study in Spine Surgery Between O-Arm and Airo Systems: Efficacy and Radiation Exposure. World Neurosurg 118:e175-e184. https://doi.org/10. 1016/j.wneu.2018.06.148

21. Hecht N, Kamphuis M, Czabanka M, Hamm B, König S, Woitzik J, Synowitz M, Vajkoczy P (2016) Accuracy and workflow of navigated spinal instrumentation with the mobile AIRO(®) CT scanner. Eur Spine J 25:716-723. https://doi.org/10.1007/ s00586-015-3814-4

22. Czabanka M, Haemmerli J, Hecht N, Foehre B, Arden K, Liebig T, Woitzik J, Vajkoczy P (2017) Spinal navigation for posterior instrumentation of $\mathrm{C} 1-2$ instability using a mobile intraoperative CT scanner. J Neurosurg Spine 27:268-275. https://doi.org/10. 3171/2017.1.Spine16859

23. Joaquim AF, Tan L, Riew KD (2020) Posterior screw fixation in the subaxial cervical spine: a technique and literature review. J Spine Surg 6:252-261. https://doi.org/10.21037/jss.2019.09.28

24. Mikhail CM, Dowdell JE 3rd, Hecht AC (2020) Posterior fusion for the subaxial cervical spine: a review of the major techniques. Hss j 16:188-194. https://doi.org/10.1007/s11420-019-09722-x

25. Oikonomidis S, Beyer F, Meyer C, Baltin CT, Eysel P, Bredow J (2020) Insertion angle of pedicle screws in the subaxial cervical spine: the analysis of computed tomography-navigated insertion of pedicle screws. Asian Spine J 14:66-71. https://doi.org/10. 31616/asj.2019.0053

26. Rienmüller A, Buchmann N, Kirschke JS, Meyer EL, Gempt J, Lehmberg J, Meyer B, Ryang YM (2017) Accuracy of CT-navigated pedicle screw positioning in the cervical and upper thoracic region with and without prior anterior surgery and ventral plating. Bone Joint J 99-b:1373-1380. doi: https://doi.org/10.1302/0301620x.99b10.Bjj-2016-1283.R1

Publisher's Note Springer Nature remains neutral with regard to jurisdictional claims in published maps and institutional affiliations. 